\title{
ASSESSMENT OF RADIOGRAPHIC SCREEN-FILM SYSTEMS: A COMPARISON BETWEEN THE USE OF A MICRODENSITOMETER AND A DRUM FILM DIGITISER
}

\author{
F. R. Verdun ${ }^{1, *}$, M. Pachoud ${ }^{1}$, D. Bergmann ${ }^{2}$ and E. Buhr ${ }^{2}$ \\ ${ }^{1}$ University Institute for Applied Radiophysics, Grand-Pré 1, CH-Lausanne, Switzerland \\ ${ }^{2}$ Physikalisch-Technische Bundesanstalt (PTB), Bundesallee 100, D-38116 Braunschweig, Germany
}

\begin{abstract}
A high-end drum film digitiser (Tango, Germany) and a calibrated linear microdensitometer developed by PTB were used to assess the modulation transfer function (MTF) and the noise power spectra (NPS) of 3 mammographic screen film systems at optical density levels of 0.8, 1.5 and 2.5. The use of a drum scanner to assess MTF and NPS data appears to be adequate but requires an appropriate characterisation of the scanner to verify its internal noise level and its MTF. It is further necessary to calibrate the scanner output in terms of visual diffuse optical densities. Processing of two-dimensional digital data of grating images need to be more strictly defined for accurate MTF measurements of screen-film systems. Nevertheless, even now it seems to be feasible to use commercially available high-end and well calibrated scanners to assess screen film systems. This is especially important for quality assurance purposes because important parameters of screen film systems such like MTF and NPS can now be determined without using sophisticated microdensitometers which are not commercially available.
\end{abstract}

\section{INTRODUCTION}

Film digitisers are becoming increasingly common in medical environments because they produce data offering important advantages such as image handling, image transfer and image archiving over films. One field where the quantitative evaluation of film radiographs is important is radiation therapy, where films can be used for dosimetry. Film digitisers can also potentially be used as microdensitometers to assess the modulation transfer function (MTF) or Wiener spectra of films. In such a context, it is essential that tests are applied to characterise film digitisers in order for check their adequacy for the intended uses ${ }^{(1-5)}$.

In the framework of the fourth research programme funded by the Commission of the European Communities (CEC), a set of tests were proposed to characterise film digitiser performances ${ }^{(6)}$. The aim of this work was to verify if - after having fully characterised a commercially available drum film digitiser-one could measure MTF and noise power spectra (NPS) of mammographic films with a reasonable precision.

\section{MATERIALS AND METHODS}

\section{Drum scanner}

A high-end drum film scanner (output linear in transmittance-12 bits, type: Tango, Heidelberger Druckmaschinen, Germany) was used in this study. The characteristics of the drum film digitiser have been previously published ${ }^{(6,7)}$. The spatial resolution of the system was assessed using a test film (Sine Patterns, USA $)^{(8)}$ where sinusoidal modulations

*Corresponding author: Francis.Verdun@chuv.ch have been printed in the range of $0.375-80 \mathrm{~mm}^{-1(9)}$. Figure 1 shows the MTF obtained in the vertical direction when using the test film pattern. It appears that for this type of film, the MTF remains $>70 \%$ at spatial frequencies $<35 \mathrm{~mm}^{-1}$. This data set will be used to correct the MTF measurements performed on the different mammographic screen-film systems involved in this study.

The noise characterisation of the drum scanner was performed at different optical density levels using a set of double-sided radiochromic films (Gafchromic MD/ 55; Nuclear Associate, USA). Variation of the optical density levels of the radiochromic film were produced by irradiating the film at different dose levels on a conventional ${ }^{60} \mathrm{Co}$ radiotherapy unit. The NPS data were determined by digitising the films with a spot size of about $16 \mu \mathrm{m}$ and a reading pitch of $2541 \mathrm{dpi}$ (dots or samples per inch). A matrix of 2048 pixels $\times$ 2048 pixels was acquired and Fourier-transformed after having subtracted the dc part of the optical density. Figure 2 presents the NPS obtained when digitising a radiochromic film having an optical density of 1.6. From the nature of this type of film (no silver halide crystals) it is expected that its NPS is considerably lower than the NPS of radiographic films (Results and discussion). These measurements can be used to estimate the upper level of the extra noise coming from the drum scanner.

\section{Microdensitometer}

The microdensitometer used in this study has been developed by PTB and was especially designed to assess radiographic films. A picture of this device is shown in Figure 3. The film sample is positioned on a high-precision $x-y$ translation stage. The actual film position is measured with linear encoders with sub-micrometer precision. An illuminated slit 


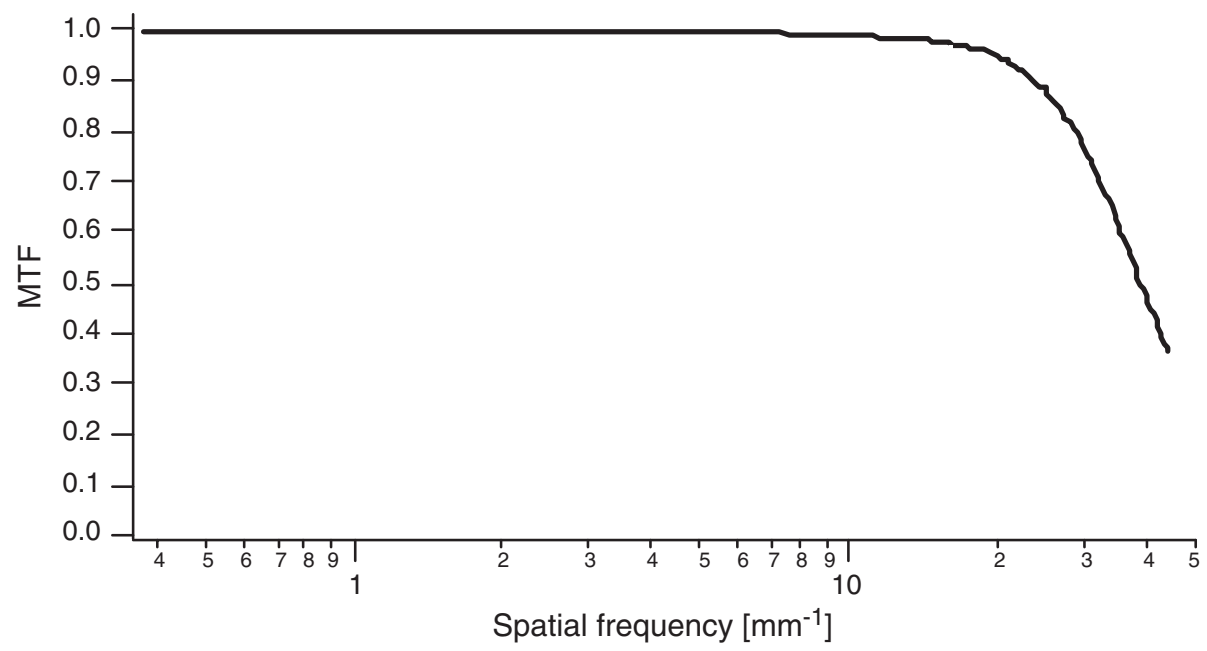

Figure 1. MTF of the drum scanner measured using the Sine Patterns test film in the vertical direction with a scanner spot size of $\sim 16 \mu \mathrm{m}$ and a digitising pitch of $2541 \mathrm{dpi}$.

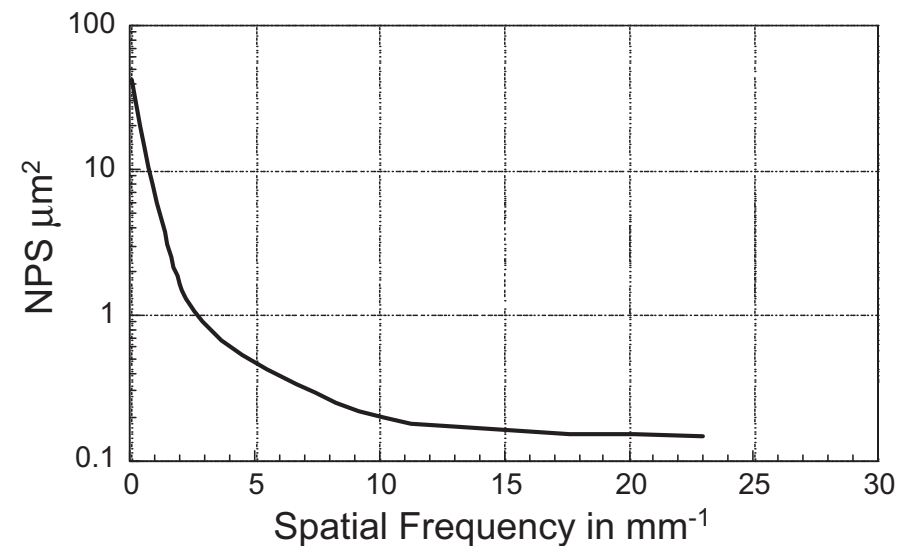

Figure 2. NPS of the drum scanner measured using an almost noise-less radiochromic film at an optical density level of 1.6. The acquisitions were performed using a scanner spot size of $\sim 16 \mu \mathrm{m}$ and a digitising pitch of $2541 \mathrm{dpi}$.

(15 $\mu \mathrm{m}$ wide and $8 \mathrm{~mm}$ long) is imaged onto the film with a high-end objective lens with unity magnification.

While the film sample moves perpendicular to the slit, a specially designed, very low noise light detector collects the transmitted light. Care was taken to meet the spectral requirements for the measurement of visual densities according to ISO 5-3. The transmitted light is, in general, spatially distributed within the half sphere due to scatter effects. The light collection efficiency is almost uniform with regard to the spatial direction: the Callier quotient of the microdensitometer is about 1.02 (Figure 4), which shows for a medical X-ray film the relationship between the measured microdensities and the macroscopic diffuse optical densities (measured according to ISO 5-2 and ISO 5-3). The microdensitometer can thus be regarded as a 'linear microdensitometer'. This is an important prerequisite to correct measured MTF and NPS data of film samples for the MTF of the microdensitometer.

The MTF of the microdensitometer is determined by the width of the scanning slit and the numerical aperture of the lens is used to image the scanning slit. Figure 5 shows the measured MTF of the microdensitometer. The extra noise added by the microdensitometer to sample signals increases with the density of the samples: the NPS of the microdensitometer is $<0.005 \mu \mathrm{m}^{2}$ for densities $<2$ and reaches $0.5 \mu \mathrm{m}^{2}$ for a density of 3 . It is thus 


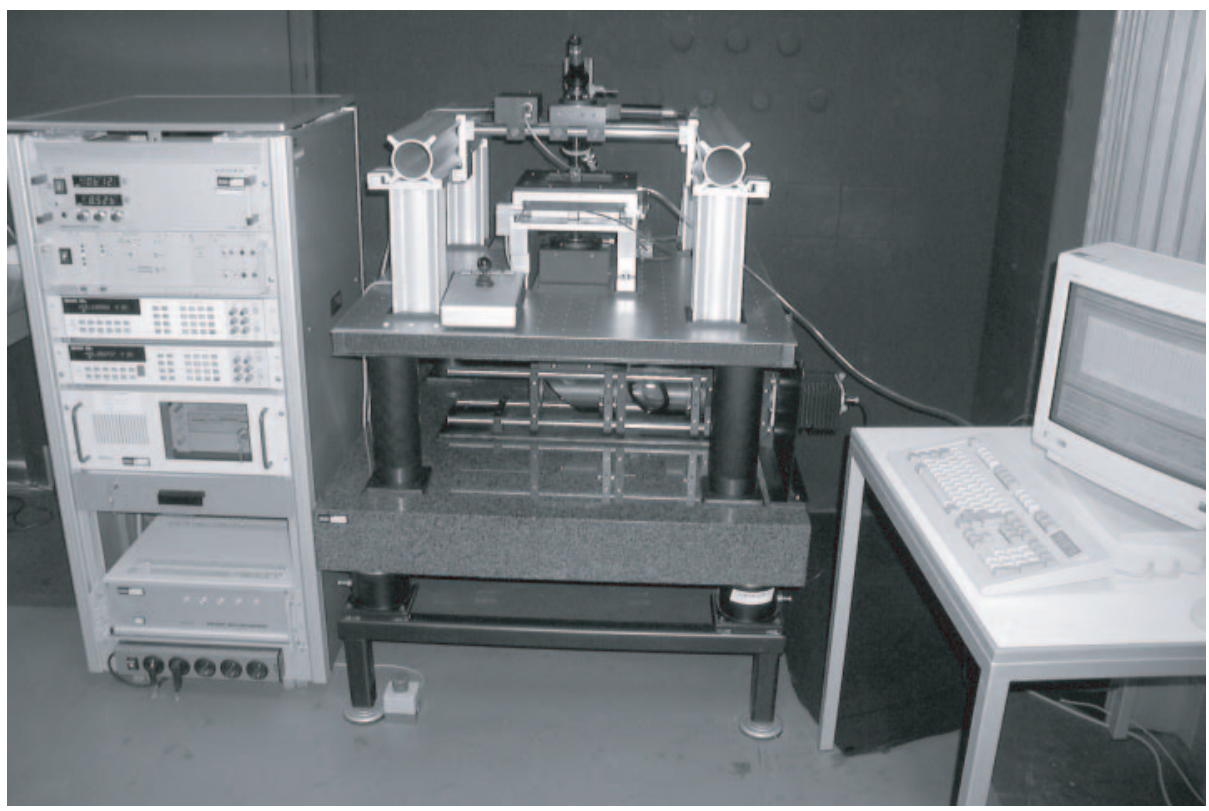

Figure 3. Picture of the reference microdensitometer of PTB used in this study.

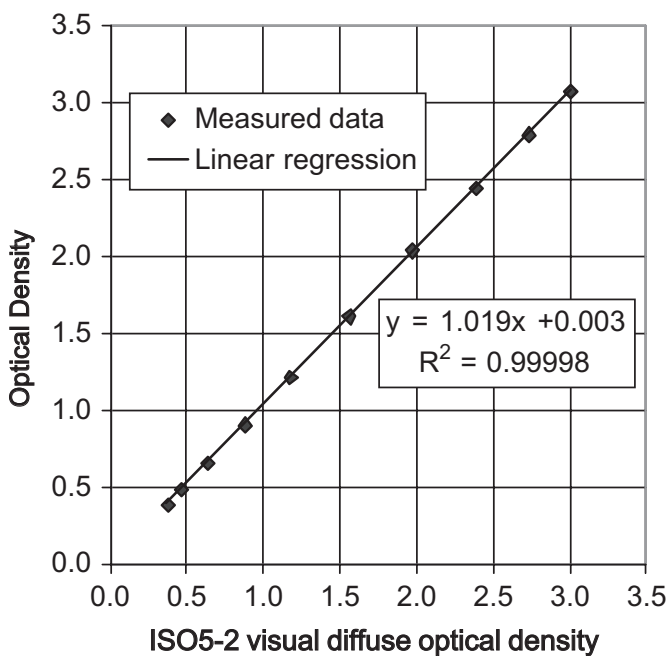

Figure 4. Linearity of the microdensitometer of PTB: Microdensity vs. visual diffuse optical density measured according to ISO 5-2 and ISO 5-3.

smaller than the NPS of typical film samples by more than two orders of magnitudes and can thus be neglected.

\section{Film screen systems}

Three mammographic screen-film systems (Fuji AD-M, Kodak Min R 2190 film with MinR

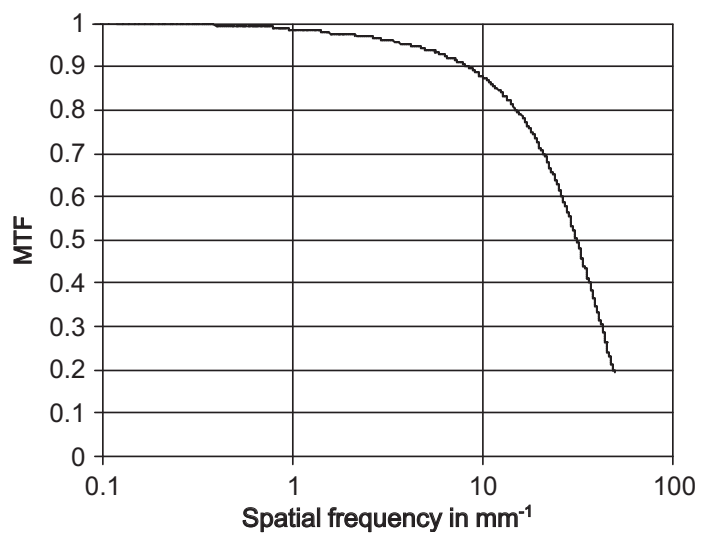

Figure 5. Measured MTF of the microdensitometer.

2000 and MinR screens) were involved in the comparison. The films have been acquired using a home designed measurement bench, which allows the variation of the distance between the focal spot and the image detector in a wide range (i.e. from 0.5 to 6.0 $\mathrm{m}$ ) to measure the sensitometric (or density) curve of the screen-film system, i.e. the response of the system to air kerma variations. Air kerma measurements have been performed using a Radcal Dosemeter connected to a 10X5-6M (6 $\mathrm{cm}^{3}$, Radcal, Monrovia, USA) traceable to the Swiss Federal Office of Metrology (METAS). 


\section{FILM SCANNER VERSUS FILM MICRODENSITOMETER}

The films have been exposed using a Toshiba mammography unit using a high voltage value of $28 \mathrm{kV}$ with an Mo-Mo anode filter combination. According to the standard ISO 9231-3, an additional filter of $2.1 \mathrm{~mm} \mathrm{Al}(99.9 \%$ purity) was placed in the beam in order to obtain a beam HVL equal to $0.63 \pm 0.02 \mathrm{~mm}$ eq. Al. Film processing was performed using a Kodak M35 system with a total processing time of $90 \mathrm{~s}\left(35^{\circ} \mathrm{C}\right.$, using a Kodak chemistry). Film processing was controlled according to the German standard DIN V 6868-55.

The films required to assess the MTF were exposed using a copper resolution test pattern containing the following square wave spatial frequencies:

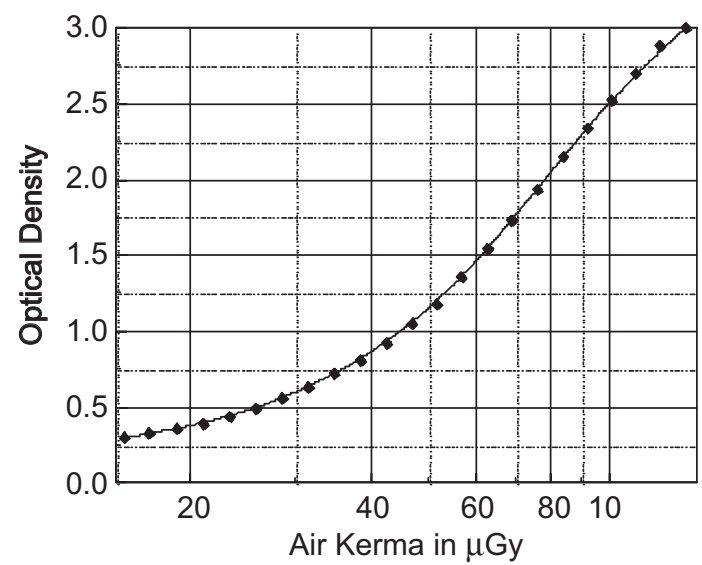

Figure 6. Density curve of the Kodak Min-R 2000-Min-R 2190 system required for the MTF calculation of the system.
$0.025-20 \mathrm{~mm}^{-1}$. The processed films were measured with the drum scanner and the microdensitometer. The microdensitometer signals were evaluated by means of a grating analysis method similar to the method described in the German standard DIN $6867-2$, which was originally developed to determine the MTF of general purpose screen-film systems. The MTF results were corrected for the MTF of the microdensitometer. The processed films were scanned with the drum scanner and the digital image data were evaluated by applying the Coltman method ${ }^{(10)}$.

For each screen-film system, uniformly exposed areas at optical densities $0.8,1.5$ and 2.5 were prepared to estimate the NPS. From the microdensitometer scans one-dimensional NPS data were extracted using a data processing algorithm described elsewhere ${ }^{(11)}$. The image data obtained with the scanner were evaluated as described in Drum scanner sub-section.

\section{RESULTS AND DISCUSSION}

Figure 6 shows the sensitometric curve of the Kodak Min-R 2000-Min-R 2190 system. For each of the systems involved in the study, such a density curve was established. The data obtained were systematically in good agreement with the data provided by the manufacturers. These sensitometric curves have been used to convert optical density values into air kerma values in the process of MTF evaluation.

Figure 7 shows, as an example, the comparison between the MTFs for the Kodak Min-R 2000Min-R 2190 system. The MTFs were obtained from

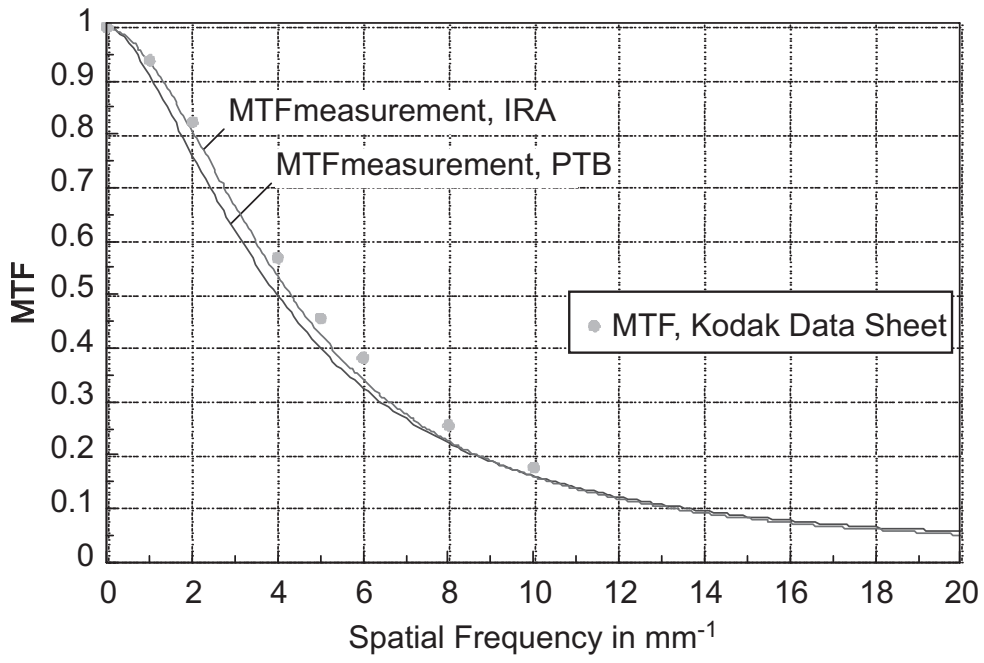

Figure 7. Comparison of the MTF of the Kodak Min-R 2000-Min-R 2190 obtained at PTB by means of a microdensitometer with the one obtained using the drum film scanner involved in the study. Data provided by the manufacturer are also shown. 



Figure 8. Comparison of the NPS of the Kodak Min-R 2000-Min-R 2190 obtained at PTB by means of a microdensitometer with the one obtained using the drum film scanner involved in the study (a) at an optical density level of 0.8 ; (b) at an optical density level of 1.5 and (c) at an optical density level of 2.5 .

the same set of films with a microdensitometer and a film drum digitiser. The data provided by the manufacturer, as far as available, have also been added to Figure 7. The first MTF assessment using the drum film digitiser was performed without a proper calibration of the scanner with respect to visual diffuse optical density. This introduced relative differences of $5-8 \%$ between the 


\section{FILM SCANNER VERSUS FILM MICRODENSITOMETER}

two techniques. After proper calibration of the drum film digitiser with respect to visual diffuse optical density and after consideration of the scanner MTF a much better agreement of $\sim 3 \%$ has been systematically achieved. In spite of the good agreement between the two techniques, it appeared that the drum film digitiser systematically tends to slightly overestimate the MTF. This phenomenon might be due to the fact that different light scatter properties between the film used to assess the MTF of the drum film digitiser (and used for data deconvolution) and the mammographic films might exist (i.e. thickness, colour, material, etc ).

Figure $8 \mathrm{a}-\mathrm{c}$ present the NPS for Kodak Min-R 2190 screen with the films Kodak Min R 2000 for 3 different optical densities $(0.8,1.5$ and 2.5$)$. The results show that the internal noise of the scanner, assessed by means of a radiochromic film is about one order of magnitude lower than the noise measured on the X-ray films, comparing with Figure 2. One can thus estimate that the noise level added by the scanner is $<10 \%$. The differences between the results obtained with the drum scanner and the microdensitometer are in the range of $\pm 10-20 \%$, in the interesting range of spatial frequency (i.e. up to $20 \mathrm{~mm}^{-1}$ ), when dealing with relatively low optical density levels (i.e. up to optical density of $\sim 1.5$ ). One has to notice that this relative difference increases significantly (in the range of 30-40\% for spatial frequencies of up to $20 \mathrm{~mm}^{-1}$ ) when dealing with optical density value $>2.0$ (Figure $8 \mathrm{c}$ ). A noticeable deviation between the results provided by the reference microdensitometer and the drum film digitiser appears to be $>20 \mathrm{~mm}^{-1}$ (Figure $8 \mathrm{a}-\mathrm{c}$ ). However, this range of spatial frequencies is of marginal interest in the field of diagnostic radiology.

\section{CONCLUSIONS}

The use of a drum scanner to assess MTF and NPS data appears to be adequate but requires an appropriate characterisation of the scanner to verify its internal noise level and assess its MTF. It is further necessary to calibrate the scanner output in terms of visual diffuse optical densities. From the good agreement obtained for the three screen film system tested in the framework of the study, it seems feasible to use commercially available high-end and well calibrated scanners to assess screen-film systems, e.g. for quality assurance purposes.

\section{ACKNOWLEDGEMENT}

The authors gratefully acknowledge the financial support of the Swiss Federal Office for Education and Science (Grant no. 99.0739, Fifth European Research Programme No FIGMCT 2000 00036).

\section{REFERENCES}

1. Meeder, R. J. J., Jaffray, D. A. and Munro, P. Tests for evaluating laser film digitizers. Med. Phys. 22, 635-642 (1995)

2. Yin, F.-F., Giger, M. L., Doi, K, Yoshimura, H., Xu, X.-W. and Nishikawa, R. M. Evaluation of imaging properties of a laser film digitizer. Phys. Med. Biol. 37, 273-280 (1992).

3. Ishimitsu, Y., Arai, K., Taira, R. K. and Huang, H. K. Radiological laser film scanner sampling artifact. Comput. Med. Imaging Graph. 14, 25-33 (1990).

4. De Wagter, C. and Mersseman, B. Characteristics of a commercially available film digitizer and their significance for film dosimetry. Phys. Med. Biol. 43, 1803-1812 (1998).

5. Yip, K. L., Lubinsky, R., Whiting, B., Muka, E. and Kocher, T. E. Performance analysis of medical $x$-ray film digitizers. Proc. SPIE. 1231, 508-525 (1990).

6. Lim, A. J. Image quality in film digitizers: testing and quality assurance. In: RSNA Categorial Courses in Physics. (Oak Brook IL, Radiological Society of North America) pp. 183-193 (1996).

7. Hoeschen, C., Buhr, E. and Hoeschen, D. Requirements for scanners used for digitizing medical radiographs. In: Proceedings of the Nineth Aachener Kolloquium 'Signaltheorie' (Aachen, RWTH) pp. 87-90 (1997)

8. Sine Patterns, USA. Available on http://www. sinepatterns.com

9. Verdun, F. R., Hoeschen, C., Pachoud, M., Moeckli, R., Valley, J.-F. and Schnyder, P. The necessity of a quality assurance programme for a radiological film digitiser. Radiat. Prot. Dosim. 90, 253-258 (2000).

10. Coltman, J. W. The specification of imaging properties by response to a sine wave input. J. Opt. Soc. Am. A 44, 468-471 (1954).

11. Dainty, J. C. and Shaw, R. Image Science. (London: Academic Press) (1974). 